\title{
Mojca K. Šebart and Andreja Hočevar, Delusions of Preschool Education: Does Anyone Care about the Process Quality Anymore? Verlag Dr. Kovač, 2019; 133 pp.: ISBN: 978-3-339-11112-8
}

Reviewed by DAMIJAN ŠTEFANC ${ }^{1}$

In the scholarly monograph Delusions of preschool education: Does anyone care about the process quality anymore?, authors Mojca K. Šebart and Andreja Hočevar examine a very topical question in the field of pedagogical theory, especially with regard to preschool education. They start by asserting that quality preschool education is a central pillar of any quality education system, emphasising that many research studies confirm that preschool attendance has a considerable influence on children's current and future development, learning and academic achievements.

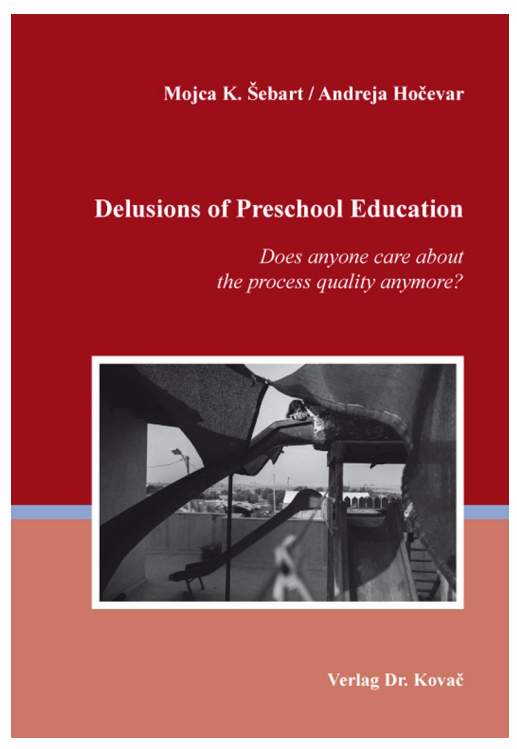
In addition, it contributes significantly to equity in education in general, especially when disadvantaged children are concerned. It is thus not surprising that preschool education has become an interesting topic for education policymakers in European and global contexts, with a very significant impact on school policies in national contexts. Analysing international documents in the first part of the book, the authors demonstrate that the political tendencies generated and maintained by some key institutions (e.g., the OECD, the IMF, the EU) encourage countries to adopt measures that improve access to preschool education and that enable as many children as possible to participate in it. However, they do not encourage good quality programmes that could actually ensure every child's optimum development. Rather, they promote preschool education solutions that clearly strengthen the ideology of attaining the learning outcomes of preschool children and ensuring children are ready to enter school. This aspect specifically links institutional

1 Faculty of Arts, University of Ljubljana, Slovenia; damijan.stefanc@ff.uni-lj.si. 
preschool education to learning outcomes in the child's later schooling, as well as to their achievements in adulthood. Investing resources in preschool education programmes is similarly primarily considered as investment in people, that is, "human capital". Such programme "quality" foregrounds the relationship between the length of participation in preschool education, learning outcomes (typically in national external tests and international knowledge assessment tests) at entry and higher levels of education, and investment in preschool education. According to the authors, what really matters is the medium- and longterm high profitability of public resources invested in preschool education, and decisionmakers are interested less in programme quality than programme efficiency (the "greatest possible profitability"). It is therefore not surprising that the authors find that international studies of preschool education predominantly focus on establishing its effectiveness, and on the development of the characteristics and knowledge of children that will help them respond to the demands of the labour market. Needless to say, this is reflected in preschool practice, too. The authors rely on an analysis of studies done in Nordic countries, concluding that current social and pedagogical preschool education guidelines have lost their significance. Nowadays, preschool education is perceived as investment in children. Consequently, preschool teachers' attention is being (re-)directed to economic standards and the preschool education quality indicators that are directly related to knowledge standards and children's learning outcomes. Preschool teachers' primary task is now evaluating children's learning outcomes and supervising each child's learning. This foregrounds children's readiness for school and risks scholarising preschools.

In the second part of the book, the authors demonstrate that Slovenia is following these tendencies. They carry out an analysis of the conceptual foundations of preschool quality assessment and assurance in Slovenia since 2000, concluding that at the beginning of this millennium, Slovenia had a good concept of preschool quality assessment and assurance, which was not fully implemented for a variety of reasons, mostly related to decisionmakers and financial resources. After becoming an EU member state, Slovenia concentrated more on preschool effectiveness than quality. This is confirmed by the analysis of the emerging national system of education quality assessment and assurance, which is largely financed by EU funds and follows the financier's expectations and requirements. The authors stress that there is a real danger that such a conceptualisation of preschool quality assessment and assurance will lead to the scholarisation of preschools, which is further supported by the fact that the area of learning and teaching is understood as a priority area that preschools should consider in the process of their (self-)evaluation. 
In the last part of the monograph, the authors address preschool education in the countries of former Yugoslavia. This part of the book brings insights into the systems and conceptual solutions in preschool education quality assessment and assurance in Bosnia and Herzegovina, Croatia, Montenegro and Serbia, some of the countries that, together with Slovenia, constituted Yugoslavia until 1990. The authors write that all of these countries strive for increased shares of children participating in preschool education, but the shares nonetheless remain low, especially the shares of 1-3 year-olds. Preschool education access in these countries is significantly poorer for children in rural areas, as well as for children whose parents cannot afford to pay the fees or do not realise the importance of their children (especially of the first age group) attending preschool. Preschool children in the countries under discussion do not have equal opportunities to participate in quality preschool education, which raises the question of the equity of the education systems concerned. With regard to preschool education quality assessment and assurance, the countries apply two models: whereas Bosnia and Herzegovina and Montenegro measure preschool education quality using children's learning outcomes, Croatian and Serbian experts reject such monitoring and measuring of children's achievements. Of course, the question is how long this will remain the case, especially since the different strategic documents in the two countries emphasise the importance of lifelong learning, which relates to children's better employability when they grow up. Moreover, both countries provide a one-year preparation for school in the year before children enter school.

With their monograph, Mojca K. Šebart and Andreja Hočevar are the first in Slovenia to systematically address the political and ideological tendencies that lead, in the long term, to institutional preschool education that is primarily bound by economic efficiency, with pedagogical quality becoming an ever more marginal issue. In other words, the fundamental goals of preschool education - improving the lives of children and families, ensuring the optimum development of each child, and developing a critical, responsible and autonomous personality - are no longer in the foreground. This makes Delusions of preschool education: Does anyone care about the process quality anymore? a monograph that asks key questions in this time, not only systemic and pedagogical questions, but also wider social and ethical questions that require indepth scientific approaches. It provides convincing answers to these questions, as well. 